\title{
Levels of aerobic fitness as an unfair parameter in Algerian football training programs
}

\author{
Zerf Mohammed, Bengoua Ali, Mokkedes Moulay Idriss
}

Physical Education Institute Laboratory OPAPS, University of Mostaganem, Mostaganem, Algeria.

\begin{abstract}
Aerobic capacity is a vital factor for soccer achievement. Disclose by professionals over $\mathrm{VO}_{2}$ max of $60 \mathrm{ml} / \mathrm{kg} / \mathrm{min}$ recommended as the minimum fitness condition for male soccer players to play at leading levels. Founded on the principle kinetics analyse, which confirms that among competitive soccer players, wing-backs and central midfielders cover long distances at high speed, then by defenders and attackers. Our objective is to test 180 well-trained male senior player, first division Algerian Championship. Dived biased on their postgame. Controlled at the end of the preparatory phase before the start of the Algerian Championship 2016-2017. Tested by Cooper tests to estimate their $\mathrm{VO}_{2}$ max and body fat percent (BFP) and index body mass (BMI). As simple tools to control their optional body weight relates to their aerobic fitness. Our results support the uniform of Algerian training programmes aerobic capacity. Conclude through the present founded on kinetics analyse, which confirmed that in competitive soccer players, wing-backs and central midfielders cover long distances at high speed, then by defenders and attackers. Our results show that $\mathrm{VO}_{2}$ max $\mathrm{L} / \mathrm{min}$ was insignificant based on the postgame, where this result confirms to users the negative effect of the moderate-intensity exercise intervention and its consequences on develops of recommended levels of $\mathrm{VO}_{2}$ max relative to proper individuals programme fitness helping players to manage body weight or stroke. Disclose by professionals over $\mathrm{VO}_{2}$ max of $60 \mathrm{ml} / \mathrm{kg} / \mathrm{min}$ recommended as the minimum fitness condition for male soccer players to play at leading levels.
\end{abstract}

Keywords. Aerobic fitness, Algerian football training programs, $\mathrm{VO}_{2}$ max.

\section{Introduction}

$\mathrm{I}$ n professional soccer, the player/team's performance profile is linked to biological and environmental factors. Claims by specialists through aerobic capacity, as a significant factor that affects the final league ranking, the quality of the game and the covered distances (Bekris et al., 2016). Estimate in the case of speed performance among competitive soccer players, in the benefits of the forwards as the fastest followed by the central midfielders, the wide defenders/midfielders and then the central defenders. In fact (Hong, 2014) set that wingbacks and central midfielders cover long distances at high speed then by defenders and attackers. Confirmed by (Strudwick, 2016) as a significantly greater total distance covered during elite soccer match play, shown in the benefits of central midfielders and wide midfielders (both about 12 to $13 \mathrm{~km}$ ). Interpret by (Simini \& BertemesFilho, 2018) that midfielders are the shortest players, with the smallest amount of Fat Muscle. For the above proofs and previous studies, that advises the significant relation between $\mathrm{VO}_{2} \max$ and distance covered during a match, as much as rank order in the league of the best teams (Hoff et al., 2002). Set by Researches at $60 \mathrm{ml} / \mathrm{kg} / \mathrm{min}$ of $\mathrm{VO}_{2}$ max suggested as the minimum fitness requirement for male soccer players to play at an elite level (Almeida et al., 2018).

The aim of this study was to evaluate aerobics capacity levels as an index to estimate the injury of Algerian soccer training programs under the postgame demands. Admitted in the similar study as the most common method to enhance cardiorespiratory fitness and recover faster associate with high levels of $\mathrm{VO}_{2} \mathrm{max}$ players at $60 \mathrm{ml} / \mathrm{kg} / \mathrm{min}$ suggested as the minimum fitness requirement for male soccer players (Bompa \& Claro, 2008). As well as the most important area of any fitness program helping the active persons to control their body weight or stroke. 


\section{Methods}

The present study compared the aerobic performance of soccer players based on their different playing positions and their competitive levels through the 12-minute Cooper test. Performance in this test was assessed with players $\mathrm{VO}_{2} \max$ relative to its position game (midfielders, defenders and attackers) as well as their body composition estimated built on BMI and BFP formulas. Support by (Sathi, 2016) as an accurate measure of weight, body fat, body muscle and body mass index and keep track of weight loss goals among Sports and Fitness programs, according to (Statle, 2016).

Our goals are to anticipate differences among the groups that would make it possible to define the variables that determine the injury of Algerian soccer training programs.

\section{Participants}

A total of 180 male adult elite players, representing some teams from the league Oran years 2016-2017. Were examined by the Research Team 5 Laboratory OPAPS in parameters (anthropometric and physiological) during the transition phase of the championship-see Table 1.
(Reilly, 2003) as a better indication of an individual's state of aerobic, directly related to the physical demands and physiological cardiovascular function.

\section{Body Mass Index (BMI)}

BMI was calculated from body mass $(\mathrm{W})$ and height $(\mathrm{H})$. BMI $=\mathrm{W} /\left(\mathrm{H}^{2}\right)$, where $\mathrm{W}=$ body mass in kilograms and $\mathrm{H}=$ height in metres.

\section{Body fat percent (BFP)}

In adults (Deurenberg et al., 1991) set that the prediction formula was $\mathrm{BFP}=1.20 \times \mathrm{BMI}+0.23 \times$ age $-10.8 \times$ sex $($ males $=1$, females $=0)-5.4$. Its validity is comparable to the prediction error obtained with other methods of estimating BFP, such as skinfold thickness measurements or bioelectrical impedance.

\section{Statistical Analysis}

Data analysis was performed using SPSS 22.0 for Windows (32- bit) (IBM, Armonk, NY, USA). Data obtained from the tests showed the homogeneity of the sample, presented as mean \pm standard. Anova one way was used to determine the differences between players based on post-game as protocol integrates into this study. Although the relationship between the variables was analysed by Pearson correlations (r). All statistical significance set at 0.05 .

\section{Results}

Based on the protocol used and the results in Table 1 and Figure 1.

Our results show that there is no difference between our players under their post-game. State in the present by the insignificance of ANOVA one way in all the parameters studies and the inverse correlation between $\mathrm{VO}_{2} \max$ and body

Figure 1. Descriptive characteristics of the soccer players participating in the study.

\section{Tests and Protocol}

\section{Cooper 12-minute Run Test}

Is a popular maximal running test of aerobic fitness, in which participants try to cover as much distance as they can in 12 minutes. To estimate $\mathrm{VO}_{2}$ max (in $\mathrm{ml} / \mathrm{kg} / \mathrm{min}$ ) from the distance scored, we use the formula $\mathrm{VO}_{2} \max =(22.35 \times \mathrm{km})-11.29$. Admit by weight, fat or fatness Table 2. In the opposite of height. From that, we agree on the inadequate of Algerian programs devoted to developing aerobic capacity based on post-game recruitments. Clams by the author through $60 \mathrm{ml} / \mathrm{kg} / \mathrm{min}$ of $\mathrm{VO}_{2} \max$ suggested as the minimum fitness requirement for male soccer players to play at leading levels. Affirmed by previous studies back on the significant relation between Vo2max and distance covered during a match, test or training as well as a rank 
order and placement in the league of the best teams compared with those in the lowest-placed team (Hoff et al., 2002). Admit by (Bekris et al., 2016) as an important factor that affects the quality of the game. Estimate through $60 \mathrm{ml} / \mathrm{kg} / \mathrm{min}$ as an advantage to play in top elite leagues. Disclosed by (Silva et al., 2016) at $69 \mathrm{ml} / \mathrm{kg} / \mathrm{min}$ with individual values higher than $70 \mathrm{~mL}-\mathrm{kg}-1 \mathrm{~min}$ according to (Hong, 2014). Interpret by (Simini \& Bertemes-Filho, 2018) in the benefits of players with the smallest amount of Fat Muscle. Advanced by (Dawes, et al., 2016) via the evidence that increase of body fat or fatness is associated with decreasing capacity of aerobic fitness. Suggests as a targeted approach applied in efforts to achieve optimal improvement in physical fitness performance allied to athletics body and performance.

\section{Table 1}

Descriptive characteristics of the soccer players participating in the study based on post player's game.

\begin{tabular}{|c|c|c|c|c|c|}
\hline & & $\mathrm{n}$ & Mean \pm SD & $\mathrm{F}$ & $\mathrm{p}$ \\
\hline \multirow[t]{4}{*}{ Height (cm) } & Defender & 60 & $174.53 \pm 4.63$ & 0.08 & 0.92 \\
\hline & Midfielder & 60 & $174.18 \pm 4.89$ & & \\
\hline & Attack & 60 & $174.55 \pm 7.12$ & & \\
\hline & Total & 180 & $174.42 \pm 5.63$ & & \\
\hline \multirow[t]{4}{*}{ Weight (kg) } & Defender & 60 & $63.83 \pm 7.11$ & 1.53 & 0.82 \\
\hline & Midfielder & 60 & $62.54 \pm 6.89$ & & \\
\hline & Attack & 60 & $64.87 \pm 7.89$ & & \\
\hline & Total & 180 & $63.75 \pm 7.33$ & & \\
\hline \multirow[t]{4}{*}{ BFP (\%) } & Defender & 60 & $19.99 \pm 2.33$ & 0.25 & 0.77 \\
\hline & Midfielder & 60 & $19.93 \pm 1.95$ & & \\
\hline & Attack & 60 & $20.75 \pm 1.57$ & & \\
\hline & Total & 180 & $19.89 \pm 1.97$ & & \\
\hline \multirow[t]{4}{*}{ BMI $\left(\mathrm{kg} / \mathrm{m}^{2}\right)$} & Defender & 60 & $23.99 \pm 0.64$ & 0.06 & 0.96 \\
\hline & Midfielder & 60 & $23.08 \pm 0.45$ & & \\
\hline & Attack & 60 & $22.97 \pm 0.46$ & & \\
\hline & Total & 180 & $23.89 \pm 0.52$ & & \\
\hline \multirow{4}{*}{$\begin{array}{l}\mathrm{VO}_{2} \mathrm{Max} \\
(\mathrm{ml} / \mathrm{kg} / \mathrm{min})\end{array}$} & Defender & 60 & $57.11 \pm 3.42$ & 2.14 & 0.12 \\
\hline & Midfielder & 60 & $56.61 \pm 2.7$ & & \\
\hline & Attack & 60 & $55.86 \pm 3.8$ & & \\
\hline & Total & 180 & $56.52 \pm 3.36$ & & \\
\hline
\end{tabular}

\section{Discussion}

Based on the study design and statistical applied. Our finds confirm the evidence that $\mathrm{VO}_{2} \max$ up to $\geq$ $60 \mathrm{ml} / \mathrm{kg} / \mathrm{min}$ is beneficial physiological training response among soccer players. Admit by (Scribbans et al., 2016) at any intensity above $\sim 60 \%$ of $\mathrm{VO}_{2} \mathrm{max}$ is likely to improve maximal oxygen uptake in healthy adults. Suggest in the present through training at or greater than $\sim 60 \%$ of $\mathrm{VO}_{2}$ max to improve maximal oxygen uptake as well as the decreases body weight or stroke. Confirmed by Zouhal et al. (2013) at high-intensity intermittent methods. Supported by Thevenet et al. (2007) as a good criterion to judge the effectiveness of this exercise on the development of physiological soccer post and games recruitments. Affirmed by Fortuna et al. (2018) above the increases of distance run during the match, performed work, the number of sprints and the number of actions with the ball.

\section{Table 2}

Presents the correlations between the variables tested in the current study.

\begin{tabular}{cccccc}
\hline Pearson correlation & Height & Weight & BMI & BFB \\
\hline $\mathrm{VO}_{2}$ Max & $\mathrm{r}$ & $0.51^{* *}$ & $-0.25^{* *}$ & $-0.27^{* *}$ & $-0.28^{* *}$ \\
& $\mathrm{p}$ & .00. & .001 & .000 & .000 \\
\hline
\end{tabular}

From the above, we reach agreed that evaluation of aerobics capacity levels is a key index to estimate the injury of Algerian soccer training programs under the post-game demands. Admitted in the similar study as the most common method to enhance cardiorespiratory fitness and recover faster associate with high levels of $\mathrm{VO}_{2}$ max players at $60 \mathrm{ml} / \mathrm{kg} / \mathrm{min}$ of $\mathrm{VO}_{2} \max$ (Almeida et al., 2018), suggested as the minimum fitness requirement for male soccer players. As well as the most important area of any fitness program helping the active persons to control their body weight or stroke. Set in similar as advantage in the benefits of the top team compared with those in the lowest placed among the Norwegian elite league, according to Hoff et al. (2002). Interpret by Zouhal et al. (2013) as training body adaptation, allied to body composition management (Insel et al., 2016). Admit in this study via the levels of aerobic capacity relative to changes in body fat or percent (Mohammed et al., 2016) as effective endurance training to improve maximal oxygen uptake allied to physiological soccer demands. Conclude via this study as an unfair parameter in Algerian football programs under kinetics analyses, which confirmed that in competitive soccer players, wing-backs and central midfielders cover long distances at high speed, then 
by defenders and attackers. The case of this study confirmed by the insignificance of ANOVA one way in all the parameters studies and the inverse correlation between $\mathrm{VO}_{2}$ max and body weight, fat or fatness, see Table 2.

\section{Conclusion}

Our finds confirmed that Algerian training programs do not respect the minimal $\mathrm{VO}_{2}$ max requirement based on the different player's positions. Confirmed by kinetics analyse among competitive soccer players, where wing backs and central midfielders cover long distances at high speed, then by defenders and attackers. Affirmed by (Hong, 2014) in the benefits of wing-backs and central midfielders that cover long distances at high speed, then by defenders and attackers. Established by (Strudwick, 2016) as a significantly greater total distance covered during elite soccer match play, shown in the benefits of central midfielders and wide midfielders (both about 12 to $13 \mathrm{~km}$ ). Disclosed in the similar study as the most common method to enhance cardiorespiratory fitness and recover faster associate with high levels of $\mathrm{VO}_{2}$ max players at $60 \mathrm{ml} / \mathrm{kg} / \mathrm{min}$ of $\mathrm{VO}_{2} \max$ (Bompa \& Claro, 2008), suggested as the minimum fitness requirement for male soccer players (Almeida et al., 2018). As well as the most important area of any fitness program helping the active persons to control their body weight or stroke.

\section{References}

Almeida AMd, Santos Silva PR, Pedrinelli A, Hernandez AJ. Aerobic fitness in professional soccer players after anterior cruciate ligament reconstruction. PLoS ONE, 2018; 3: e0194432.

Bekris E, Mylonis L, Gioldasis A, Gissis I, Kombodieta N. Aerobic and anaerobic capacity of professional soccer players in annual macrocycle. Journal of Physical Education and Sport (JPES), 2016; 16(2): 527-533. doi:10.7752/jpes.2016.02082

Bompa T, Claro F. Periodization in Rugby. Auflage: Meyer \& Meyer, 2008.

Dawes JJ, Orr RM, Siekaniec CL, Vanderwoude AA, Pope R. Associations between anthropometric characteristics and physical performance in male law enforcement officers: a retrospective cohort study. Ann Occup Environ Med, 2016; 28(26): 1-7.

Deurenberg P, Weststrate JA, Seidell JC. Body mass index as a measure of body fatness: age- and sex-specific prediction formulas. Br J Nutr, 1991; 65(2) : 105114.
Fortuna M, Szczurowski J, Zabłocki T, Pałasz D, Demczyszak I. Estimation of evaluation some spirometric's parameters of football players during preparation period. Journal of Education, Health and Sport, 2018; 8(6): 69-79. doi: 10.5281/zenodo. 1252282

Hoff J, Wisløff U, Engen LC, Kemi OJ, Helgerud J. Soccer specific aerobic endurance training. Br J Sports Med, 2002; 36(3): 218-221.

Hong Y. Routledge Handbook of Ergonomics in Sport and Exercise. London: Routledge, 2014.

Insel P, Ross D, McMahon K, Bernstein M. Nutrition. US: Jones and Bartlett Publishers, 2016.

Mohammed Z, Abelatif H, Mokhtar M, Ali B. Height versus weight which cassel parameter determine pulmonary functions fitness among the algerians soccer players. J Pulm Respir Med, 2016; 6(353). doi: 10.4172/2161-105X.1000353

Sathi A. Cognitive (Internet of) Things: Collaboration to Optimize Action. New York: Palgrave Macmillan US: Palgrave Macmillan, 2016.

Scribbans TD, Vecsey S, Hankinson PB, Foster WS, Gurd $B J$. The effect of training intensity on vormax in young healthy adults: A meta-regression and meta-analysis. Int J Exerc Sci, 2016 ; 9(2) : 230-247.

Silva MJC, Figueiredo AJ, Elferink-Gemser MT, Malina RM. Assessment of biological maturation in adolescent athletes: application of different methods with soccer and hockey players. Portuguese: University the Colomba, 2016.

Simini F, Bertemes-Filho P. Bioimpedance in Biomedical Applications and Research. Cham: Springer International Publishing: Springer, 2018.

Statle S. Beacon Technologies: The Hitchhiker's Guide to the Beacosystem. Berkeley, CA: Apress, 2016.

Strudwick A. Soccer Science. Champaign, IL: Human Kinetics, 2016.

Thevenet D, Tardieu M, Zouhal H, Jacob C, Abderrahman BA, Prioux J. Influence of exercise intensity on time spent at high percentage of maximal oxygen uptake during an intermittent session in young endurance-trained athletes. Eur J Appl Physiol, 2007; 102(1): 19-26. doi: 10.1007/s00421-007-0540-6

Reilly T. Advances in Sport, Leisure and Ergonomics. London: Routledge, 2003.

Zouhal H, LeMoal E, Wong DP, BenOunis O, Castagna C, Duluc C, Owen AL, Drust B. Physiological responses of general vs. specific aerobic endurance exercises in soccer. Asian J Sports Med, 2013; 4(3): $213-220$. 